\title{
Why should I publish?
}

\author{
Por que eu devo publicar?
}

"Because it's in my blood", I once heard from a great mentor and superb writer.

$\mathbf{W}$

hy should I publish? What is the real importance of publishing a scientific article? What we want when we produce a scientific paper? A scientific publication can bring a lot to those who publish, but you cannot lose sight of what it means. First, we must clearly understand that, although the feeling of seeing the published article is rewarding, that publication is only the final step of a long way.

The research is the essential condition for progress in medicine. Testing new diagnostic tools and treatment options, stringent scientific publications play a fundamental role for humanity. Contributing in this regard, and becoming part of history are already enough reasons to get involved in this arduous task. The papers published in the peer-reviewed literature are a trustful source of information for clinical practice and future research.

Publications can bring even more to those who engage in a scientific article. It all starts with an idea or a question that remains. The potential author should then establish a method on which will be based on all the results. But perhaps the most interesting aspect of this stage of the process is how to get to that question.

Frequently, the doubts and issues come from the intense reading of scientific articles, which involves hours of dedication to national and international well-written papers. Acquiring the habit of quality reading further increases the understanding of the reasons why we should publish.

Reading articles stimulates reasoning and critical capacity, improves the understanding of future manuscripts, brings considerable consciousness and makes us think. Reliability and ethics are important in all stages of production. With a suitable method, actual results and a discussion that combines wisdom, ability to develop hypotheses and arguments with extensive knowledge of the topic discussed, further increase the chances of acceptance of publication.

Although the initiative of publishing must come from ourselves, mentors and professors play an important role encouraging young residents and fellows with whom they work, to follow their steps.

Those who publish embraces the remarkable value of studying more and staying current, enabling the researcher, under a strict medical ethics context, to offer the most validated and modern diagnostic and therapeutic options for our patients.

With patience and hard work, anyone of us can get a significant amount of scientific contribution, which brings not only paramount consequences for the career but also the respect of our peers. A fact that typically opens many and definitive doors.

The continuous process of publications assures and renews this respect. The young ophthalmologist should have in mind the bigger prizes are undoubtedly the solid respect those who share their expertise will develop for them as well as the sense of pride generated in those who has always trusted in his or her career. Together with all recognition, comes an equal responsibility, that goes far beyond a name printed. 
Finally, the main reason why we should publish is the potential ability to inspire those who read us. Most of the prolific publishers grew up admiring the authors who could put their ideas to print in an eloquent and efficient fashion. Authors who inspire people to believe this significant contribution should be part of us, should be in our blood.

I do believe.

It is in my blood. That's why.

Marcony R. Santhiago MD PhD

Editor Chefe - Revista Brasileira de Oftalmologia Departamento de Oftalmologia, Universidade de São Paulo, São Paulo, SP, Brasil. Departamento de Oftalmologia, Universidade Federal do Rio de Janeiro, Rio de Janeiro, RJ, Brasil. Department of Ophthalmology, University of Southern California - USC, Los Angeles, USA 